\title{
Supply Chain System Model of Components for Assembly Lines Based on Kanban and Milk Run Methodologies
}

\author{
Victor Hugo Oliveira dos Santos, Marcelo Albuquerque de Oliveira, and Gabriela de Mattos Veroneze
}

\begin{abstract}
Seeking to optimize the raw material supply for the assembly lines in many industries, the following case study, starting with a direct observation of a motorcycle factory and an electronics assembly factory, based on a rich theoretical analysis of the Lean wastes, describe the factories present processes and focus on developing a fast, feasible and low cost solution, gathering concepts of Kanban and Milk Run methodologies, resulting in a proposal of a system of real time management of the production status, allowing a better organization for the logistics teams of the named companies.
\end{abstract}

Key words - Lean Manufacturing, Kanban, Milk Run, Toyota Production System.

\section{INTRODUCTION}

To attend to the demand of the current competitive world market, the companies constantly need to optimize their processes and reduce their costs to achieve bigger participation scopes to customers' retention.

Since the First Industrial Revolution, companies and commerce held a competition looking for a common objective: increase their recipes, because of that, many philosophies and wholesale tools and the Toyota Production System that aimed toward the production of many items, according to the market demand.

In Toyota Production System implementation, it has been defined by Shigeo Shingo and Taichii Ohno the so-called seven wastes, losses that occur daily, although many times are ignored by considered inherent to the processes. With this philosophy change, it must be searched the resolution of daily wastes, worthing the collaborators and optimizing processes.

Given such need, in this work, it is going to be approached by the companies that have been an inspiration to the project elaboration, such as the problematic, analyzed through the direct observation in the companies mentioned above.

The First evaluated company, which is referred as the F Company, is part of the electronic hub, responsible for the production of remote controls and Internet modem, with broadband and optic fiber models and signs of a pressed circuit. Its origin is from the State of Amazonas, being an outsourced assembler to many telephone companies and the Internet packs providers, with the medium daily production of thirty thousand modems and fifty thousand remote controls, divided in thirty-eight assembly lines.

Submitted on August 23, 2021

Published on October 27, 2021.

Victor Hugo Oliveira dos Santos, Federal University of Amazonas, Brazil.

(e-mail: victorhos32@gmail.com)
The second company, which is going to be referred to as the $\mathrm{H}$ Company, belongs to the two wheels hub, more specifically with the fabrication of motorcycles and 4X4 bikes. Originally, from Japan, the multinational in question has a big market share in the field of its activities, with the medium daily production of ten thousand motorcycles in its assembly lines.

Within these two scenarios so much different, it has been studied a primordial activity to the execution of its activities: the input feeding to assembly lines. Independently of being the final products completely different, there is the need of feeding the lines, where enters the study analysis, to ascertain the existence of some of the seven wastes of STP.

\section{LITERATURE REVIEW}

\section{A. Total Production System}

Focused on the optimization of the factory resources, the applied methodology by Toyota comes up in an economically unstable historic moment due to the mishaps of the post Second World War with one mission: Reduce costs.

[1] defines as principal objective of the Toyota Production System (TPS) to increase production efficiency by eliminating consistent and full waste. Challenging concepts employed by American systems focused on the production of many units of few products, also called as pushed production, the Japanese manufacturer seems that a mere copy of the American productive system could be dangerous, given that the market eventually would suffer a slowdown, by the fact that these models consider everything that is produced, will be sold.

[2] lists seven main wastes found in the industrial reality: Super production; Wait; Transport; Processing; Stock; Movement and Rework, which must be mitigated or eliminated from the productive processes, aiming that the companies, become more competitive and increase their profits through the fabrication reduction costs. [3] brings that the need to fight the losses in the processes must be a nonaggregation of value to the product, also as the generation of costs, motivating, in some situations the compromise to the organization competitiveness.

[1] claims that TPS highly depends on the workers' collaboration, once they are going to be day-by-day developing productive activities on the factory floor.

Marcelo A. de Oliveira, Federal University of Amazonas, Brazil. (e-mail: marcelooliveira ${ }^{\circledR}$ ufam.edu.br)

Gabriela de M. Veroneze, Federal University of Amazonas, Brazil. (e-mail: gveroneze@ufam.edu.br) 
[4] approach that the differential of TPS is its essence, where development of people and exceptional teams, with the right directions, generates exceptional results.

This way, the companies looking for results through the implementation of the TPS work methodology must value their teams so that they can think of continuous process enhancement.

\section{B. Lean Manufacturing}

The Lean philosophy aims to the five original principles, created, and applied on the TPS, to orientate the productive chain to increase productivity and eliminate waste, maximizing the profits. Specify the value: understand what the customer sees as value and turns it as a production goal; Value Stream: identify how the intern production chain will achieve the established value; Continuous Stream: keep the constancy of production and the continuous and seamless delivery to the customers; Pushed Production: attend to the demand in accordance with the market; Continuous enhancement: search relentlessly for optimization of productive processes.

The application of these concepts needs organization, a new way of think over the company role, functions, and careers to canalize the value stream, from the conception to the releasing, from the request to the delivery, from the raw material to the clients' hands, according to [5].

[6] have described the ten crucial steps to the Lean system implementation. These are: (1) Leadership and satisfaction of the client; (2) People involvement; (3) Alliance with a supplier; (4 (4) Source quality; (5) Management on sight; (6) Productive maintenance; (7) Fast tools change; (8) Push the production; (9) Reduce the time cycle; and (10) Control and reduction of costs. With the control and reduction of costs, it can be done a parallel with the seven wastes proposed by [7].

\section{Just in Time}

The Just-in-Time (JIT) philosophy has emerged in Japan after the Second World War, where Toyota Motor Company has been the precursor of the pilot project, according to [8]. The first objective of the JIT philosophy is to eliminate waste in the production system, according to [7]. The Just-in-Time work system has as its aim what the Japanese call as "Zero stock", where there is searched for working only with the minimum referring to equipment, raw material, inputs and finished product's stock.

The biggest challenge of JIT is to achieve the essential index related to the minimum stock and don't stop the assembly lines that demand supplies relentlessly.

So that it can occur, there is a recurrent need of the understanding in real time of the product's availability and its deliveries together with their suppliers, consequently, a very strong control by Supply Chain. Avoiding stops in the assembly lines by lack of inputs, without the need of raw material, half-finished products or finished products. To the TPS, the stock is stopped money.

\section{Milk Runs}

The Milk Run methodology can be defined as a way of collection that defines a good route that aims to reduce the lead-time of delivery and collecting of materials, once it concentrates the caption of many items to the factory.

According to [9], the Milk Run turns into a method of piece calling (stock management), such as Kanban, using the philosophy of Just-in-Time. The materials programmed collecting on the suppliers aimed to and is presented in Fig. 1.

i. Minimize the shipping cost using the total capacity of the transport vehicle (volume or weight), with the best possible scripting to the data collected on the suppliers.

ii. Potentialize the stock turns to discipline the supplier. Increase the supply frequency; feed the assembler only with needed pieces, in the needed quantities, in the requested hour and in the pattern packages.

iii. Reduce the vehicle's number in the assembler and improve the coordination of these vehicles in their factory plant. Once the pieces are collected in each supplier, there is a reduction in the number of how each vehicle of collecting has a predetermined scheduled to the delivery of the collected pieces, there is a bigger control in the service of these vehicles by the assembler, to the discharge of the pieces due to the labor and needed equipment to this operation.

iv. Streamline the charge and discharge of materials, aiming to eliminate idle times when the collecting vehicle of pieces is in the suppliers and on the own assembler.

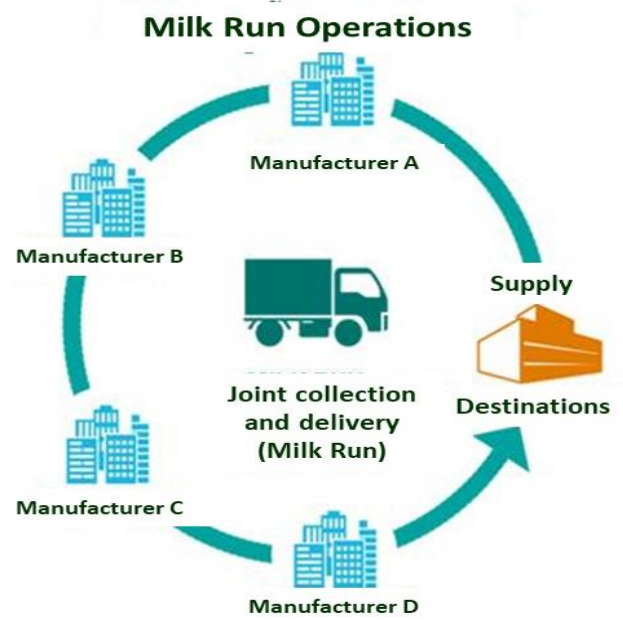

Fig. 1. Milk Run Methodology [11]. 
v. Level the daily stream of materials receiving

vi. Improve the services provided, the pattern package, the performance of charge/pallet and get faster on charge and discharge of vehicles of programmed pieces collecting.

vii. Reduce the stock level on the suppliers. Obtaining the production program necessary to supply the assembler (programmed day to the collected pieces and quantity to be provided) the suppliers can program themselves to obtain their raw materials and manage the stock level on their chains.

viii. Tool to the Just-in-Time system. The O Milk Run figures like a process to implantation of a Just-in-Time system within suppliers and the assembler.

ix. Better administration of reusable packages. The packages are patterned, and the logistical operator replenishes the supplier in accordance with his needs and due to the collecting pieces program. Therefore, each supplier will have a number of certain packages that will be on the collecting pieces cycle (supplier assembler).

x. Reduction of damages during transportation. With the patterned packages and the transport operation being done by prepared vehicles to execute this task, reduce a lot the problem of damages on the pieces during transport and movement, through the studies carried out to balance the charge on the vehicle (layout) and don't damage the packages, keeping always the same people, trained, involved in the programmed collecting, driver of the logistical operator, forklift drive and of the own assembler.

According to [10], there are three reasons that attribute a huge implementation of Milk Run around the world.

i. Clarification of the distribution costs impacts, that usually are included within the acquired product's prices.

ii. Reduction on the cost with transportation due to the use of few transport batches and big material mix.

iii. Enhancement on production lines and stock accuracy due to the synchronization of the deliveries.

According to [12], with the right application of Milk Run methodology, the main gains acquired by the companies, retreats on the transportation cost, besides enabling the routes optimization and decreasing deliveries Lead Time, through the multiple collect in only one route.

\section{E. Kanban}

[9] says that the control tool of stock Kanban, that is integrant part of the Toyota Production System makes part of Just-in-Time wok approach, aiming only to supply the factory unity, according to the necessary items, within the necessary quantities, in the necessary moment, with the quality to supply the final assembly line without losses and generation of stocks, according to [7].

The purpose is to keep a physical stream integrated to the pieces on the supply chain and streamline the delivery of the final product to the consumer eliminating all the losses and stocks. According to [13], it is to keep the products stream according to the demand's need to aggregate value to the completely logistical chain, Pipeline.
According to [14], the principal focus of Kanban is to define, with accuracy, the status about what needs to be done, consequently, the Kanban, when rightly applied, allows that tasks might be prioritized and that work streams are defined, such as the control over delivery lead-time of the task here in question. The Kanban process shows clearly the processes that require more attention, focusing on the risk reduction of no attendance, which allows a bigger flexibility to define priority actions of a team, related to their deliveries and demands.

\section{Methodology}

Initially, it has carried out the consultation to the literature that fitted on a basis to the initial analysis over the problematic referring to the possible wastes commonly found in the industrial reality. Therefore, through direct observation, it has been established the concepts acquired on the bibliographic revision.

Through a study case, qualitative research over the feeding processes of assembly lines has been carried out and a proposal of idealized enhancement, on behalf of daily activities development optimization.

\section{A. Model Development}

In this spot for the work, it is going to be approached by the problematic, analyzed through the direct observation in two companies of Manaus Industrial Hub, such as the solution proposal directed to the resolution mentioned above.

\section{B. Study Scenario}

Initially, it has been evaluated the functioning of the components feeding to two assembly lines, aiming to identify potential enhancements on a Milk Run methodology.

\section{FINDINGS AND DISCUSSIONS}

\section{A. Activities Analysis}

Analyzing the feeding raw material method along the assembly lines of the company $\mathrm{H}$, according to Fig. 2, it is observed the presence of two feeding methods: one by aerial transport to pieces of big aggregate, and that has production in-house synchronized with the assembly line, avoiding the accumulation of stock, besides feeding by baskets and cars, usually about small pieces and components acquired from external suppliers.

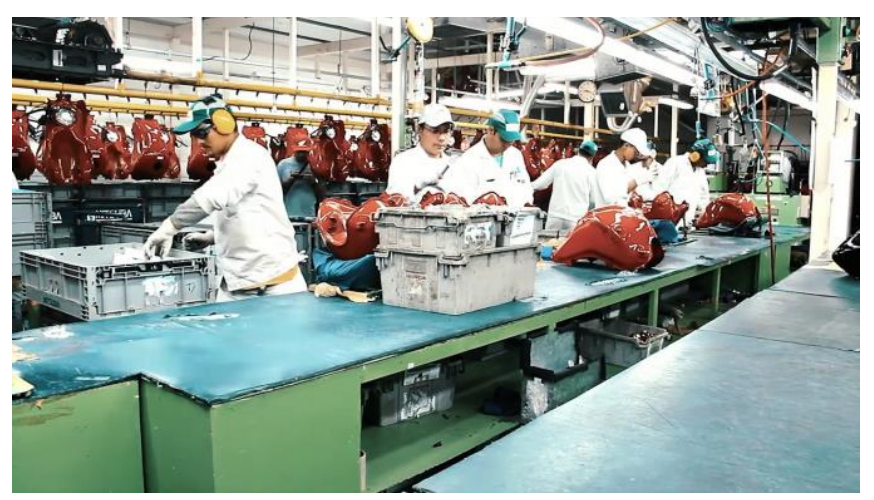

Fig. 2. Assembly Line Company H [15]. 
About the feeding functioning by baskets and cars, there is a specific sector responsible for storing, counting, movement, delivery and inputs control referred to the assembly lines, according to a scheme represented on Fig. 3.

This sector is far around two kilometers of the line, localization justified by the fact that all the components that must be delivered come from many other productive sectors spread by the factory, so the feeding sector stays in a strategic area that eases the delivery truck movement.

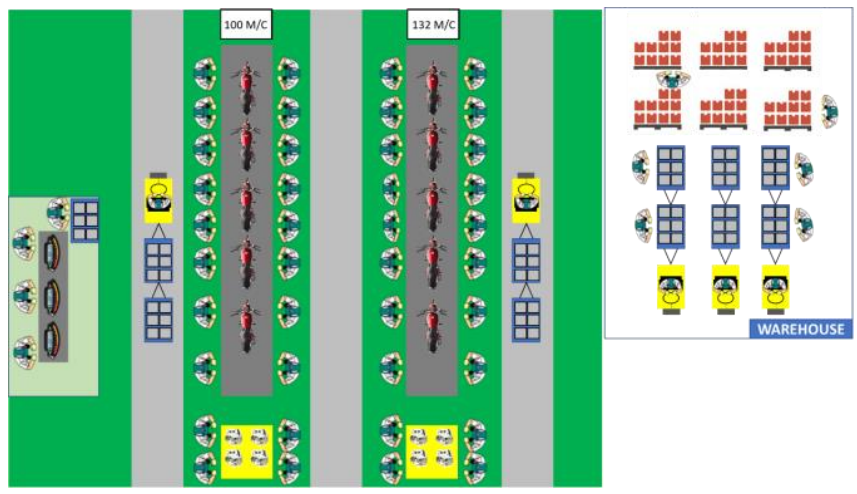

Fig. 3. Company H Feeding Stream.

An analysis way of the consumption status to the next request is given by the production follow-up, since there is a quantity pre-established by motorcycle items, it's done the calculation through the following formula,

$E=\left(Q m * \sum I m\right)-$ Minimum stock

where:

$\mathrm{E}=$ delivery;

Qm = Quantity of material on the basket;

Im - Used items by motorcycle.

Besides, conceptually, present accuracy and not occurring lines stop caused by the lack of material supply, it is necessary to evaluate the concept referred to the efficiency of such a process. Shingo points out that "invisible" loss occurs on dayto-day activities.

Now analyzing the company F condition, is found thirtyfour assembly lines, where the supply delivery functioning is given by around two to three collaborators named "feeders", these people, according to this function, walk through the assembly lines, observing or listening from the assemblers about what the next to be finished. Then, they go to the responsible by the warehouse, where are kept the components, do the request of the items and later take it to the assembly line, according to what is indicated on Fig. 4.

This path is given most of the time with the operator carrying input boxes at the post regarding on the layout. The feeders are also responsible by doing the boxes of nonfinished products movement to the transporter that take them to the warehouse, where they will be stored, tied to the clients' requests and sent to the destination.

Evaluating each line has three collaborators, on the worst scenario, only to inputs reposition activities, within thirtyfour assembly lines that work on three production shifts, it can be concluded that company $\mathrm{F}$ has on its personal board, three hundred and six people only to movement and input feeding activities. Such a great board like this, inevitably, makes questions show up about the process effectiveness, specially what refers to the collaborators needs given by the lines.

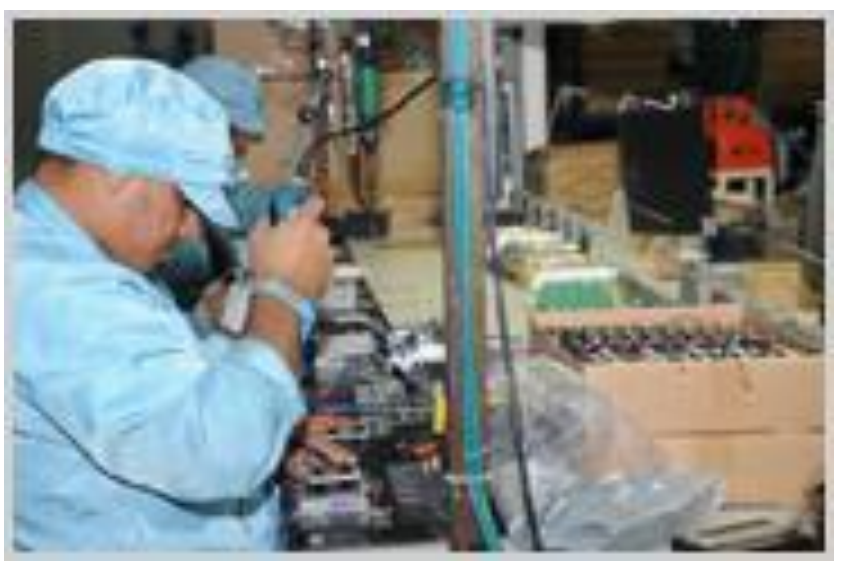

Fig. 4. Company F Assembly Line [16].

\section{B. Proposed Solution}

In both scenarios, it's noticeable the need to evaluate a way more efficient to do the assembly line feeding, in a way to avoid the stock accumulation by line (work in process), that decreases the movement of cars and collaborators who is accurate according to the requested demand by the process.

This way, this study proposes that a simple system blends the concepts of Kanban and Milk Run. The concept behind the basic idea is: Once it treats of baskets or product boxes with pre-established weights because of the present elements quantity, it is going to be used a balance that can generate $\operatorname{logs}$, those are information's that are a transcript on a more system to be managed by the responsible of the assembly lines feeding.

The idea is similar to a supermarket balance, where determined items are weighted. Its weight is converted to a numerical value by the multiplication of the value of the product's kilo and at last. It has given the final value to the client.

On the proposed application, the baskets and boxes would be put-on balances, with this, it could be guessed that one 1000 pieces basket of squared-nuts of weld from the supplier $\mathrm{x}$, for example, would have the weight $1,8 \pm 0,142 \mathrm{~kg}$ and after being consumed by the process, the weight would reduce proportionally, enabling the system analysis on real time of the value present at each step of the process through kanban.

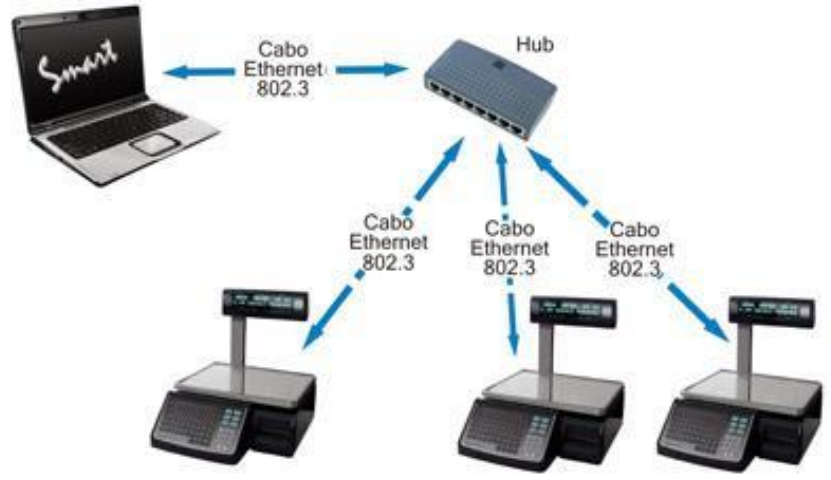

Fig. 5. Weighing Reading System [17].

Subdivided into three categories: OK, GENERATES REPOSITION REQUESTS AND CRITIC STOCK 
PROCESS, determined categories according to each evaluated item, in a way that the sector responsible by the inputs feeding can control, in real time, the consumption of the assembly line, enabling that it can be organized by item, by post and line. This way, once it is known the exact line status, the sector can determine a way of how to feed, only in one journey, all the posts that need to resupply, what would define a milk run delivery system, using fewer labor resources and with higher efficiency, according to Fig. 6.

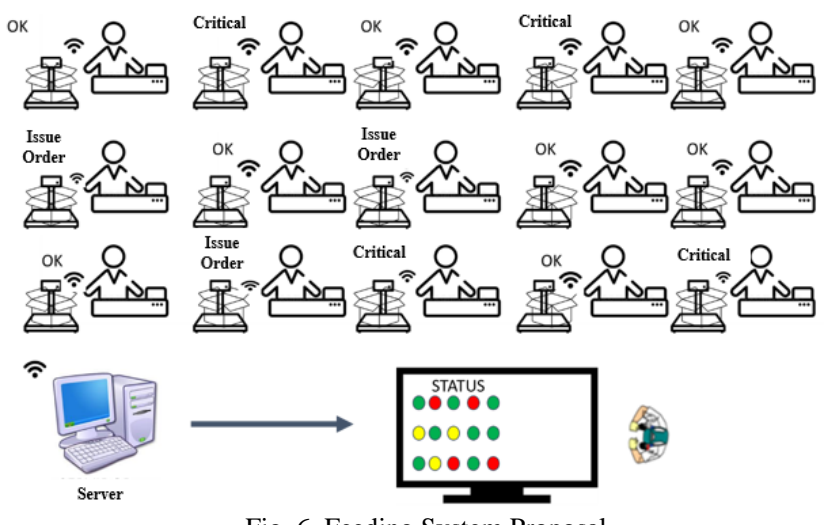

Fig. 6. Feeding System Proposal.

\section{Results Analysis}

Once the aim of this study is only the proposal of solutions, the results analysis is given through the results evaluation through the total implementation of the deliveries' methodology, also as the suggestions to its integration to the production and failures prevention.

\section{Expected Results}

Evaluating the critic situation, regarding company $\mathrm{F}$, the expectation is that occurs $67 \%$ reduction across the personnel board employed, exclusively, to movement activities of the pieces on the three production shifts.

The economic impact can be provided based on the collected data with the company F, shown on Fig. 7, regarded to the bonuses granted to the collaborators with the legal costs inherent to the nocturnal industrial activity that embraces the second and third shifts.

The value $67 \%$ refers to the possibility of a collaborator to guarantee the complete feeding of an assembly line, which mostly are "twins", that is, they have the same structure and do the assembly of identical items, simultaneously.

With the provided economy with the reduction of two hundred and four collaborators of the personnel board, to the company F, the merit of this enhancement would be the value around R\$ 501.525,16 monthly (around U\$ 91.000,00), enabling on investments with the necessary structure to project implementation, besides investments on equipment that eases the items movements, such as cars and tugs.

To the company $\mathrm{H}$, the principal merit would be to gain efficiency and increase security, as there would be a drastic decrease in the movement of tugs and car pieces, what would decrease the collision risks with other collaborators who transmitted by the assembly line, the delivery of more one item in the same shipment and the collaborator time valorization, enabling to face new challenges and activities, such as more accurate control of the company's stock.
By optimizing the accuracy of the stock, the activities of sectors related to fiscal parts, since given the legislation that governs Manaus Free Zone, also known as "Block K" dismemberment Federal Revenue that makes recurring audits as to the decrease of items produced to fee's control granted to companies in the city of Manaus, thus avoiding possible fines that the company could suffer.

\section{CONCLUSION}

Blending the theoretical concepts regarding the waste's losses, rational utilization of productive inputs, economic merit efficiency optimization, the current study, even though it portrays an execution proposal, brings a big reflection:

- Are the daily factory floor activities being evaluated strategically?

Besides that, it can be embraced the premise that the process optimization and tools analysis can be reevaluated, blended and applied in different ways, looking for results that are necessary to business reality.

In parallel to the Industrial Revolutions, the companies that did not adapt ended up losing space on market and, eventually, perished to the competitors that always adopted new strategies to the execution of their activities. In this case, the re-interpretation about the use of Kanban and Milk Run tools enables the companies $\mathrm{F}$ and $\mathrm{H}$ ways to reduce their costs, increase efficiency and, overall, directs time to their collaborators to activities that aggregate value to the final client.

Although, this study also has great development potential, not only on the systematic creation, but also on the applicable part, once a field system would allow an even clear vision around the real team needs, besides the failures and optimization potential.

Thus, it stands as a challenge to the academic community and to the companies, in loco application, its development and maturation.

\section{ACKNOWLEDGMENT}

The authors thank the Production Engineering Department (DEP) of the Federal University of Amazonas (UFAM) for their support and structure.

Special acknowledgement to the institutions and people involved to the final consolidation of this work that has been authorized through the agreement 001/2020 from the Cooperação Técnico-Científica celebrated between Fundação Universidade do Amazonas (FUA), Fundação de Apoio ao Ensino, Pesquisa, Extensão e Interiorização do IFAM (FAEPI) and the company Samsung Eletrônica da Amazônia LTDA (SEDA-M), within the project's scope of capacitation and research, which has been done by the academic unity FTUFAM. 
NIGHT SHIFT WORK JOURNEY

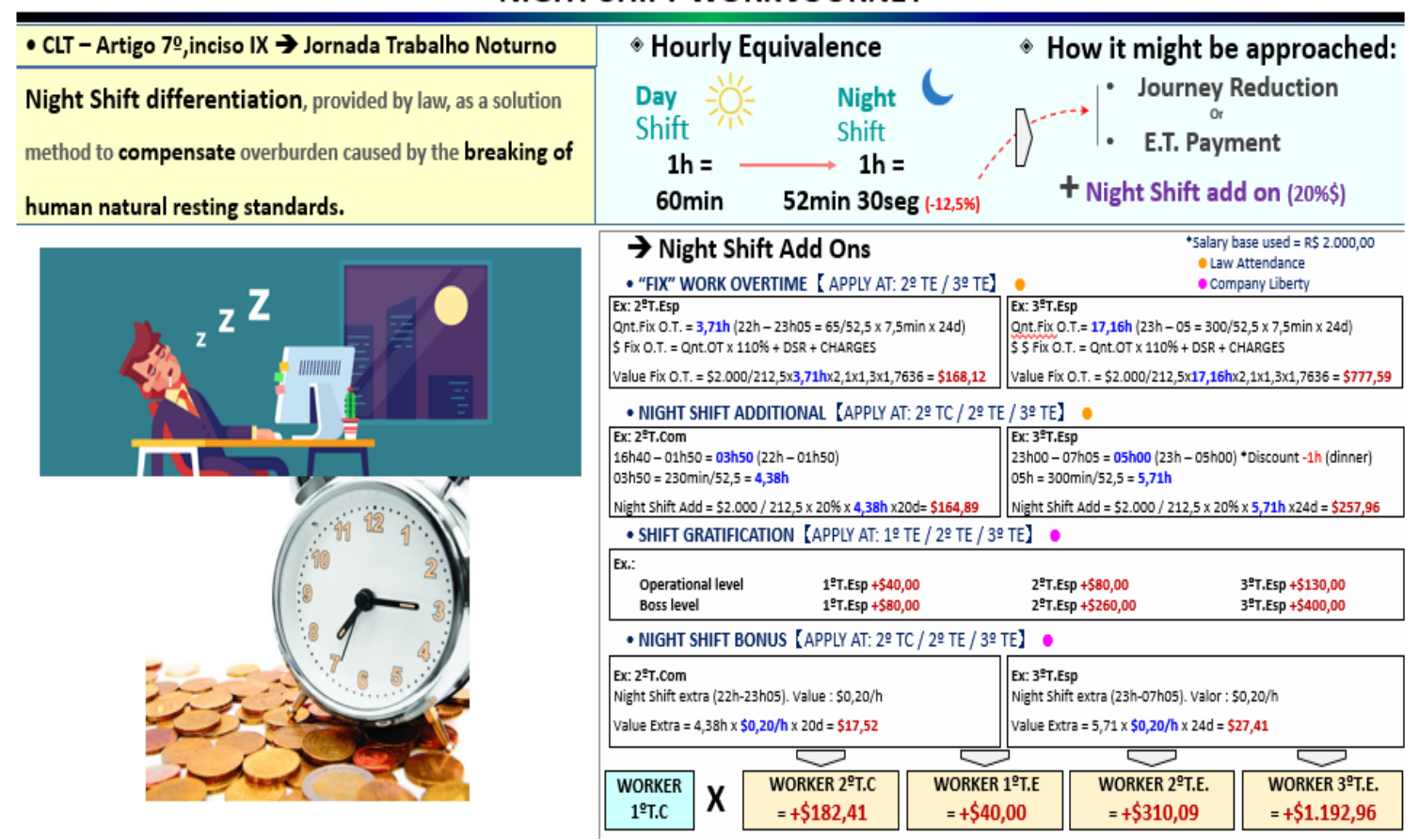

Fig. 7. Financial Results.

\section{REFERENCES}

[1] T. Ohno, Toyota Production System: Beyond Large-Scale Production. New York: Productivity Press, First Edition, 176 p., 1998.

[2] S. Shingo, A Study of the Toyota Production System. New York: Productivity Press: 257 p., 1989.

[3] C. P. Machado and V. A. G. Tondolo, Perda por ruptura em gôndola: uma análise do Sistema Toyota de Produção, na indústria alimentícia e no varejo supermercadista. Revista Gestão da Produção Operações e Sistemas, V. 9, n. 3, p. 15, 2014.

[4] J. K. Liker and D. Meier, The Toyota Way Fieldbook: A Practical Guide for Implementing Toyota's 4Ps. McGraw-Hill Companies, First Edition, 475 p., 2008.

[5] J. P. Womack, D. T. Jones, and D. Ross, The Machine That Changed the World: The Story of Lean Production-- Toyota's Secret Weapon in the Global Car Wars That Is Now Revolutionizing World ... That Is Now Revolutionizing World Industry. Free Press, First Edition, 327 p., 2007.

[6] S. F. T. Rago, E. C. Júnior, J. M. Banzato, and R. A. Moura, Atualidades na gestão da manufatura. São Paulo: IMAM, 2003.

[7] S. Shingo, The Shingo Production Management System: Improving Process Functions. New York: Productivity Press, First Edition, 238 p., 1992.

[8] D. F. Tubino, Manual de planejamento e controle da produção. São Paulo: Atlas, 1997.

[9] D. A. Moura and R. C. Botter, Caracterização do sistema de coleta programada de peças, Milk Run. RAE eletrônica, Vol. 1, No. 1, p. 1$14,2002$.

[10] T. Nemoto, K. Hayashi, and M. Hashimoto, Milk-run logistics by Japanese automobile manufacturers in Thailand. Procedia-Social and Behavioral Sciences, Vol. 2, No. 3, p. 5980-5989, 2010. https://doi.org/10.1016/j.sbspro.2010.04.012.

[11] CCA Express, Sistema Milk Run de Coletas Programadas. Available at: <https://www.ccaexpress.com.br/blog/sistema-milk-run-de-coletasprogramadas/>.

[12] P. Setiani, H. Fiddieny, E. B. Setiawan, and D. E. Cahyanti, Optimizing delivery route by applying milkrun method. In: Conference on Global Research on Sustainable Transport (GROST 2017), 2018. https://doi.org/10.2991/grost-17.2018.65.

[13] M. J. Ploos van Amstel, Managing the pipeline effectively. Journal of Business Logistics, v. 11, n.2, p. 1-25, 1990.

[14] H. Lei, F. Ganjeizadeh, K. P. Jayachandran, and P. A. Ozcan, Statistical analysis of the effects of Scrum and Kanban on software development projects. Robotics and Computer-Integrated Manufacturing, v. 43, p. 59-67, 2017. https://doi.org/10.1016/j.rcim.2015.12.001.

[15] C. De Biasi Comunicação Audiovisual, Moto Honda da Amazônia. Available at: 〈https://www.youtube.com/watch?v=iqToIrbvRo8>

[16] Flex Industries, Conheça nossos processos. Available at:

https://www.flex-am.com.br/?pg=fotos.

[17] Absoluta Balanças, Balanças Filizola. Available at $\langle$ http://www.absolutabalancas.com.br/filizola/platina.htm〉.
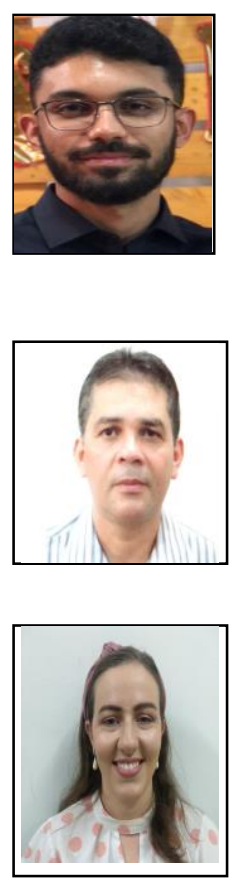

Victor Hugo dos Santos is a student is a student of Production Engineering at the Federal University of Amazonas, and researcher under SUPER project.

Marcelo Oliveira is an Adjunct Professor of Department of Production Engineering and member of Master Program in Production Engineering, Federal University of Amazonas. He has published several Research Papers related to Engineering area.

Gabriela Veroneze is an Adjunct Professor, Department of Production Engineering and member of Master Program in Production Engineering, Federal University of Amazonas. She has published several Research Papers related to Engineering area. 